\title{
Marcos Fernández y su versión española de los diálogos latino-franceses de Philippe Garnier
}

(Amsterdam, 1656; Estrasburgo, 1659)*

Daniel M. Sáez Rivera

\section{CpenEdition}

\section{Journals}

Edición electrónica

URL: https://journals.openedition.org/cher/9092

DOI: $10.4000 /$ cher.9092

ISSN: 2803-5992

Editor

Presses universitaires de Strasbourg

Edición impresa

Fecha de publicación: 1 diciembre 2010

Paginación: 173-201

ISBN: 978-2-35410-029-2

ISSN: 1968-035X

\section{Referencia electrónica}

Daniel M. Sáez Rivera, «Marcos Fernández y su versión española de los diálogos latino-franceses de Philippe Garnier», reCHERches [En línea], 5 | 2010, Publicado el 17 diciembre 2021, consultado el 25 enero 2022. URL: http://journals.openedition.org/cher/9092 ; DOl: https://doi.org/10.4000/cher.9092

\section{(c) () (ㅇ)}

Ce(tte) œuvre est mise à disposition selon les termes de la Licence Creative Commons Attribution -

Pas d'Utilisation Commerciale - Partage dans les Mêmes Conditions 4.0 International. 


\section{Marcos Fernández y su versión española de los diálogos latino-franceses de Philippe Garnier (Amsterdam, 1656; Estrasburgo, 1659)*}

Daniel M. Sáez Rivera

Universidad Comlutense de Madrid

\section{Bio-biblio-topografía de Marcos Fernández}

Dado el complejo periplo vital de Marcos Fernández, que enseñó español por gran parte de Europa, iremos trazando los principales sucesos y desempeños de su vida, así como las ocasiones de publicación de su obra, al compás de ciertos hitos geográficos.

\section{Salamanca}

Aunque desconocemos el lugar de nacimiento de Marcos Fernández, podemos lanzar algunas suposiciones a partir de sus usos lingüísticos, si aceptamos la hipótesis de Inés Fernández Ordóñez (2001) de que los usos dialectales actuales coinciden a grandes rasgos con los antiguos. De este modo, dado que Marcos Fernández es leísta, sobre todo de persona

* El presente trabajo fue posible gracias al apoyo del Proyecto del MECyT, «Procesos de gramaticalización en la historia del español (III)» (PROGRAMES3), referencia FFI20080828/FILO, en el que la obra entera de Marcos Fernández constituye una de las fuentes primordiales. Aparte, me gustaría agradecer a Marie-Hélène Maux-Piovano la invitación a pronunciar en la Universidad de Estrasburgo, el 29-X-2009, la conferencia homónima que es el punto de partida de este artículo. También le agradezco su ayuda en la elaboración de este trabajo, al igual que a Mónica Castillo Lluch, Araceli López Serena Ana Mancera, y Luis Pablo Núñez, que aportaron ideas, artículos en prensa y comentarios diversos a un primer borrador del texto. 
y en singular, aparte de laísta e incluso loísta de plural en alguna ocasión (Sáez Rivera 2008a: 921-922), sin duda había de ser castellano, según la subdivisión dialectal de Inés Fernández Ordóñez (1999: 1360). Dentro de Castilla podemos precisar más en Salamanca, a la luz de dialectalismos de la obra de Fernández como «carabear» (Fernández 1655: 264), que el DRAE marca como propio de Salamanca, con la siguiente definición: «Descuidarse, holgar, distraerse». Las referencias a la ciudad y la provincia de Salamanca menudean además en su obra.

Ahora bien, quizá aprendiera ese y otros salmantinismos en la Universidad de Salamanca, donde dice que estudió "Logica i Filosofía» (Fernández 1647 : 153) y después enseñó lengua española y francesa (Fernández 1647 : [A1]r). En todo caso, resulta más fácil que fuera a estudiar allí si ya vivía en los alrededores, sobre todo teniendo en cuenta que no parece que su familia tuviera muchos recursos económicos.

En cuanto a la fecha de nacimiento, podemos aducir dos datos entresacados de su obra y entrelazables de alguna manera, inspirándonos en Bareau (1977: 167-168):

1. en la Olla podrida (Fernández 1655: 163), el narrador autobiográfico situado en Münster confiesa tener 33 años a la hora de un sufrido lance con una barbera casi violatoria, aunque podemos tomar la cifra de edad como una alusión burlesca a la edad de la muerte de Cristo;

2. en la Instruction espagnole accentuée (Fernández 1647:[A1]r), Fernández comenta que ya es profesor en Münster.

Si aceptamos el dato 1 como correcto y descontamos 33 años de 1647, el resultado de la fecha de nacimiento de Fernández sería circa 1609, un año de nacimiento nada descabellado para haberle dado tiempo de formarse académicamente antes de salir de España.

\section{París}

La siguiente noticia que tenemos de Fernández es la de su salida de España, quizá por heterodoxo (al menos esa es la hipótesis de Collet-Sedola 1996: 165).

Tenemos dos posibilidades para señalar como año de expatriación:

1. 1627: ya que en la Olla podrida (Fernández 1655: 23) dice llevar 27 años tratando a la nobleza francesa.

2. 1631: pues en la Instruction espagnole (1647: 153) confiesa que hace 16 años que enseña a la nobleza europea. 
Parece que su primer lugar de destino hubo de ser París, donde ejerció como maestro en la corte a nobles y cortesanos, al formar parte del cortejo de María de Médicis y del círculo hispanoportugués del médico marrano Montalto (que trató a la misma reina), y del escritor Carlos García (Bareu 1969; Pelorson 1977).

\section{Países Bajos}

Don Marcos sigue a María de Médicis en su exilio a Bruselas (1631). En la misma corte de Bruselas y en la universidad de Lovaina, Fernández dice ejercer como maestro de lenguas (Fernández 1647: [A1]r, 153). Se le atribuye la corrección de la Grammaire espagnole (Bruselas: Jan Mommaert, 1639) de César Oudin, de la que Fernández reniega (Fernández 1647: 152), criticando además al antiguo secretario de lenguas del rey francés (aunque Oudin sea su principal fuente gramatical).

\section{Alemania}

Radicado desde al menos 1647 en Münster, ciudad sobre la que versará su Olla podrida a la española (1655), de esta época en Alemania deben datar sus clases al conde de Pötting, que luego fue embajador en Madrid 1664-1674 y que debió aprovechar las lecciones de su maestro, de lo que es prueba el buen español de los Diarios que escribió en España, editados modernamente por Nuño Nieto (1990).

Fruto directo de la labor pedagógica de Fernández es una gramática de español en francés (no parece que Fernández llegara a aprender el alemán), con mucha influencia -malgré lui- de Oudin, y que debió de servir de apoyo en sus propias clases. Se trata de la Instruction espagnole accentuée (Colonia: Andrea Bingio, 1647)

\section{Holanda}

Establecido en Amsterdam ya en la década de los 50, ejerce allí como profesor de español de la burguesía local, mucha de origen judío, llegando a ser maestro de español de figuras tan señeras como el impresor Daniel Elzevier. Se publica el resto de su obra: 
1. Ramillete espiritual, compuesto de la salutación angélica i oración dominical (s. i., [La Haya], 1650): unas poesías religiosas ${ }^{1}$.

2. Nomenclator en castellano, francés y flamenco (Colonia, 1654)2 ${ }^{2}$ fruto de un posible aprendizaje del flamenco sería esta nomenclatura o vocabulario temático, en tres idiomas, publicada aún en su anterior país de residencia, Alemania.

3. Olla podrida a la española (Amberes[=Amsterdam]: Felipe van Eyck, 1655): con falso pie de imprenta, no se publicó en Amberes sino en Amsterdam, donde Van Eyck tenía su oficina (Vaíllo 2006 :153-154). ${ }^{3}$

4. Gemmulae linguarum/ Dialogue en quatre langues (Amsterdam: Luis \& Daniel Elzevier, 1656): versión española de los diálogos originales de Philippe Garnier, objeto principal del presente trabajo.

5. Dialogues en cinq langues Espagnolle, Italienne, Latine, Françoise, \& Allemande. (Strasbourg: Chez les Heritiers de Feu Eberard Zertzner, 1659): segunda edición del compendio dialogal con inclusión del español.

No conocemos más obras de Fernández. Cuando este escribió la Olla podrida (1655) y publicó su versión del Gemmulae ya debía de contar con alrededor de 50 años, una edad algo avanzada para la época. Puesto que no tuvo control de la reedición de su traducción dialogal, es posible que ya hubiera muerto en el intervalo que va de 1656 a 1659.

\section{Bio-biblio-topografía de Philippe Garnier}

Otro tanto casi podemos hacer para dar cuenta de la vida itinerante de otro maestro de lenguas de una de cuyas obras hizo traducción Fernández: Philippe Garnier, nacido en Orléans, fl. 1596, hubo de salir de Francia por sus ideas protestantes, enseñó en las universidades alemanas de Estrasburgo, Giessen y Leipzig, aunque volvió a su ciudad natal en 1621, lo que se contradice con el hecho de que los eruditos del xix fijen su muerte en Leipzig en $1655^{4}$.

1 Obra localizada por Carlos Vaíllo (2006: 157); edición en preparación por Sáez y Vaíllo.

2 Extraemos la noticia bibliográfica de Niederehe (1999, n. $\left.{ }^{\circ} 728\right)$, pero no hemos podido localizar ningún ejemplar.

3 Edición parcial en Arellano (2005) y Sáez Rivera (2008c); ed. en preparación de Sáez y Vaíllo.

4 Acerca de la vida y obra de Garnier con más detalle, ver el artículo de Luis Pablo Núñez (y su bibliografía) en este mismo número de Recherches: «Ediciones e historia textual de los diálogos plurilingües de Philippe Garnier ». 
Como es habitual -recordemos el caso de César Oudin, por ejemplo-, publicó toda una serie de obras que desde la perspectiva del tiempo podemos considerar como un programa editorial en toda regla unido a su propio proyecto pedagógico de enseñanza de lenguas, fundamentalmente o inicialmente el francés a hablantes de alemán y conocedores del latín.

Así, su primer trabajo es una gramática del francés en latín (la costumbre de escribir en tal lengua clásica una gramática de lengua vulgar es especialmente típica del ámbito germanófono ${ }^{5}$ en el que Garnier se radicó). Se trata de los Praecepta gallici sermonis ad pleniorem perfectioremque ejus linguae cognitionem necessaria tum brevissima tum facillima (Argentorati[=Estrasburgo]: impensis L. Zetzneri ${ }^{6}, 1607$ ), de cierto éxito editorial, con diversas reediciones ${ }^{7}$. Aparte de la gramática, aunque nunca llegaría a publicar un diccionario general, Garnier también llegó a confeccionar un libro de proverbios: Thesaurus adagiorum gallicolatinorum redditorum in usum utriusque linguae studiosorum, ex variis cum recentioribus tum antiquioribus authoribus collectorum, tempori et alphabeto accommodatorum. Thrésor des proverbes français expliqués en latin (Frankfurt: a costa de D. Custodis, 1612). De fortuna un poco menor, solamente tuvo una segunda edición en 1625, en Frankfurt, a costa de J. de Zetter.

En cambio, mejor fortuna tuvo su colección de diálogos, bajo la denominación latina de Gemmulae o 'gemitas' o -mejor- 'perlas', de modo que Gemmulae linguarum equivaldría a algo así como 'perlas de lenguas', en el sentido de fragmentos preciosos, que conviene guardar, sobre todo en la memoria (que era como se trabajaba pedagógicamente con esta especie de diálogos en más de una lengua, aparte de como ejercicios de traducción) ${ }^{8}$.

La primera edición localizada data de 1610, y consiste en una colección de diálogos a varias columnas en francés, alemán y latín: Gemmelloe [= Gemmulae] Gallicee linguœe, Cuivis nationum generi Gallias adeunti quàm primè necessarice; Novo \& singulari studio Gallicè, Latinè \& Germanicè conscripte, \& nulli antehac vise; novissime emissae à Philippo Garnerio

5 Cf. Sáez Rivera (2008: 865-1075).

6 Los Zetzner eran una dinastía de impresores asentada en Estrasburgo desde el Renacimiento (Meyer 2008: 122).

7 2. ${ }^{a}$ ed., 1618: Argentorati: herederos L. Zetzner; 2. ${ }^{a}$ ed., 1624/1631: Argentorati: herederos L. Zetzner; 3. ${ }^{\mathrm{a}}$ ed., 1621: Aurelia[=Orléans] : Jean Nyon; 3. ${ }^{\mathrm{a}}$ ed., 1625: Paris: A. Bacot; 3. ${ }^{a}$ ed., 1632: Rhotomagi[=Rouen] : J. Cailloué; 3. ${ }^{a}$ ed., 1638 (cum Charles Maupas, Grammaire et syntaxe Françoise): Rhotomagi: J. Cailloué.

8 Cf. Sáez Rivera (2005a). 
Aurelianensi Gallo, Linguxe Francice in Celeberrima Giessensium Academia Professore ordinario (Argentorati: Sumptibus Lazari Zetzneri Bibliopol., 1610), reeditada por el mismo impresor en 1616. Ya en 1620, el mismo Lázaro Zertzner añade una versión anónima al italiano, que se mantiene en sus ediciones de 1622 y 1625, y parece que se transmite a los Quatro dialogi di Garnero, con alcune curiosità che seguitano, molto utile e necessarie per li amatori della lingua italiana: tre sonetti di Petrarcha, proprietà di molte provincie d'Europa, documenti d'Isocrate, varie historie, proverbii. Ultima editione molto più corretta che la prima (Ginebra: G. di Tornes, 1627).

En 1634 se renueva la traducción al italiano, obra esta vez de un tal Lucas Donato: Gemmulae Gallicae linguae, latine et Germanice ita adornatoe, accessit insuper ad hanc ultimam editionem nova genuini Idiomatis Itali versio, studio et opera L. Donato (Argentorati: [s.n.], 1634).

Probablemente derive de esta versión la que publica por primera vez en los Países Bajos la famosa dinastía impresora de los Elzeviros, en 1637: Gemmulae Linguarum, Latinae, Gallicae, Italicae, et Germanicae Studio \& opera Philippi Garnieri... \& L. Donati... (Lugd. Batavorum[=Leyden]: Ex Off. Elseviriorum, 1637). Esta versión se reedita en 1641 y 1648, mientras que paralelamente los herederos de Lucas Zetzner siguen imprimiendo su propia versión, aunque en Frankfurt, no en Estrasburgo: Gemmulae gallicae linguae, latine et germanice ita adornatae ut exinde facili ac jucundo quopiam labore lingua gallica addisci queat. Accessit insuper ad hanc ultimam editionem nova genuini idiomatis italici versio... studio et opera L. Donati,... (Francofurti: impensis haeredum L. Zetzneri, 1644).

El español se añade al compendio en una versión triple con diferentes combinaciones cuatrilingües, de 1656, según traducción de Marcos Fernández, probablemente por encargo de su propio alumno Daniel Elzevier, que debió de prestarle un ejemplar -de los guardados en su oficinade la colección de coloquios de Garnier con el francés, alemán y latín, más la versión italiana de Donato:

1) Latín, francés, italiano, español:

Garnerii, Philippi, Lucæ Donati \& M. Fernandez: Gemmulae linguarum, Latino, Gallice, Italicee \& Hispanicee (Amstelodami[=Amsterdam] : Apud Ludovicum \& Danielem Elzeviros, 1656)

2) Francés, español, italiano, alemán:

Garnier, Philippe, Marcos Fernández \& Luca Donati: Dialogues en quatre langues: française, espagnole, italienne, et allemande (A Amsterdam: Chez Louys \& Daniel Elzevir, 1656) 
3) Francés, español, italiano, neerlandés flamenco:

P. Garnier; M. Fernández,; L. Donati ; J. H. Glasemaker: Dialogues en quatre langues, françoise, espagnole, italienne et flamende $=$ T'samen-spreekingen in vier talen, Frans, Spaens, Italiaens en Neerlants ; Door P. Garnier, in 't Frans; M. Fernández, in 't Spaens; L. Donati, in 't Italiaens; en I. H. Glasemaker in 't Neerlants, vertaalt/ Par P. Garnier, François; M. Fernández, Español; et L. Donati, Italien (À Amsterdam: chez Louys et Daniel Elzevier, 1656)

En la versión con el español de la Gemmulae, se reproduce el prólogo en latín 'al cándido lector' («Candido lectori», p. [3]) de ediciones anteriores del compendio. El título del compendio se traduce por primera vez al francés, al igual que se suprime de forma inaudita la columna latina, en los Dialogues en quatre langues: française, espagnole, italienne, et allemande, encabezados por una poesía laudatoria «A Monsieur Philippe Garnier, Professeur de la langue Françoise en l'Université de Giesse»(p. 3), por Christophorus Abrahamus de Steinbach, también reaprovechada desde hace décadas, al igual que el resto del texto (con la salvedad de la traducción española de Fernández) ${ }^{9}$. De igual modo sólo contiene lenguas vulgares la colección que recoge el texto de los diálogos en francés, español, italiano y neerlandés flamenco (en versión de J. H. Glasemaker), de nuevo sin la versión latina.

Finalmente, la Gemmulae "vuelve a casa» poco antes de «morir», rebautizada como Dialogues: en 1659 se publica de nuevo en Estrasburgo, y por un Zertzner, la última edición del compendio, por primera y postrera vez en cinco lenguas:

Garnier, Philippe, [Marcos Fernández, Lucas Donati], y Philemon Fabri [ed.]: Dialogues en cinq langues Espagnolle, Italienne, Latine, Françoise, \& Allemande. (A Strasbourg. Chez les Heritiers de Feu Eberard Zertzner. 1659)

El encargado de la revisión del texto fue un tal Philemon Fabri, que añade además un nuevo prólogo en forma de "Auis au Lecteur» (p. [1]). El tal Fabri debió de retocar bastante el texto español, que muestra diversas variantes con respecto a su probable fuente, los Dialogues en quatre langues y la Gemmulae linguarum ${ }^{10}$.

9 Esta es la edición que seguiremos en nuestro análisis del texto español: hemos consultado el ejemplar de París, BnF, sign. X-25482.

10 Pretendemos dar cuenta en una edición crítica de la versión hispánica de la Gemmulae/ Dialogues, que tenemos en preparación. 


\section{Características principales del texto}

\section{Contexto histórico-lingüístico}

Podemos atrevernos a señalar que la Gemmulae/ Dialogues de Garnier es un magnífico ejemplo de lo que Balibar $(1985,1991)$ bautizó como colingüismo de las clases altas europeas, que -con el molde retórico y gramatical común del latín-, aprendían varias lenguas vulgares, el italiano, el francés y el español, principalmente, según el enriquecimiento de la hipótesis de Balibar que expusimos en Sáez Rivera (2008a: 102-104). En este contexto lingüístico, el manual original recoge el francés, el latín y la lengua vulgar del alumno, el alemán. El italiano se añade por su propio predicamento como aún lengua internacional (cf. Sáez Rivera 2008b), así como por contacto comercial y cercanía con Suiza, donde de hecho se publica una de las versiones.

En el caso de Estrasburgo y Alsacia, cuando se publica la colección en 1610 por primera vez, la región formaba parte todavía del Sacro Imperio Germánico, la población en grueso hablaba el dialecto alemánico y las clases altas aprendían francés, incluso haciendo un viaje y estancia en París, conforme se muestra en los mismos diálogos de Garnier. En cambio, cuando se publica en 1659 la última versión del compendio, de nuevo en Estrasburgo, con el español, el territorio ya ha empezado a pasar a Francia.

De este modo, aunque el apetito francés por Alsacia data de al menos el siglo XIV y los franceses ya intentaron su conquista a mediados del siglo XVI, no es hasta después de la guerra de los Treinta Años, que castigó mucho a la región, cuando la Alta y la Baja Alsacia (y la ciudad de Estrasburgo con ellas) empiezan a formar parte del reino de Francia, al menos de forma nominal por la Paz de Westfalia (1648); sin embargo, la dominación efectiva de Francia no se confirma hasta la entrada de Luis XIV en Estrasburgo en 1681 (Meyer 2008: 149-174).

\section{Novedad de Garnier}

Dentro de este contexto, la colección dialogal de Garnier destaca por el hecho de que une dos tradiciones de enseñanza de lenguas, no siempre del todo convergentes:

- por la temática recuerda a los diálogos para la enseñanza de lenguas vernáculas de la tradición que arranca especialmente de los diálogos con diccionarillo de Noel de Berlaimont, en un original franco-flamenco de 
1536 que se fue enriqueciendo con diversas lenguas (el español en 1551) y expandiendo por toda Europa hasta incluso el siglo xIx ( $c f$. Bourland 1933, Rossebastiano 2003 y Pablo Núñez 2007 [en prensa])

- por el estilo (con oralidad fingida muy lograda) Garnier entronca con la tradición de diálogos renacentistas para la enseñanza del latín, con Erasmo de Rotterdam y sus Coloquios familiares (1518) a la cabeza, pero también (y sobre todo) con Luis Vives y su Exercitatio Linguae Latinae (1538); ambos trataban de enseñar un latín hablado y hablable (cf. Breva-Claramonte 1987)

\section{Títulos-personajes; resumen; paralelos}

Para saber el contenido de cada diálogo de los escritos por Garnier, basta con echarle un vistazo al título, que -siguiendo la tradición del género del que forma parte, el diálogo escolar- se ve acompañado del Dramatis Personnae del coloquio, esto es, de los nombres e incluso a veces profesiones o caracterización social de los personajes.

A continuación, repasaremos el contenido de los cuatro diálogos. A colación del título en español de cada diálogo y del nombre de los personajes intervinientes, estamparemos un resumen del texto e indicaremos los diversos paralelos o antecedentes, a veces quizá fuentes, que podemos encontrar en otros ejemplos del género en la época ${ }^{11}$ :

[1] «Coloquio primero. De Pasear. Iuan, Pedro, i Donato xardinero» (título $y$ personajes)

Resumen: varias situaciones (característica típica de los diálogos de Garnier): 1) visita una huerta o jardín; 2) invitación a cenar.

Paralelos: 1) Julliani (1659): Nomenclature du Sieur Julliani... Ensemble les Dialogues Familiers (París: J.-B. Loyson, 1659), [Diálogo primero] «Descripción de un jardin: el amo y el conuidâdo"; Estevan Barnabe (1660): Discursos familiares Con Algunos Proverbios, Historias, y Fabulas. (Viena: Matheo Riccio), «El primo discurso Del yrse à passear, y del comer y bever»; 2) Minsheu (1599): Pleasant and delightfull dialogues, "Diálogo tercéro, de un combíte, entre çinco cavalléros amígos, llamádos, Guzman, Rodrígo, don Lorénço, Mendoça, y Ossorio, un maestre sala, y un paje, en el qual, se trata, de cosas perteneciéntes a un combíte con otras pláticas, y dichos agúdos».

11 Extraigo los datos de Sáez Rivera (2008a), passim. 
[2] «Coloquio segundo. Del viage de Francia. Bartolome, Pablo, Francisco, David cochero, Jacob, i Gerardo el mesonero, Carlo, i Tileman criados, Susana, i Ana criadas» (título y personajes)

Resumen: diálogo de viaje y posada, con la originalidad de que se concreta el desplazamiento en París y Estrasburgo, con mención de etapas del viaje, así uno de los personajes dice que «no â tres ôras que partimos de Strasburgh» (pág. 62), y poco después se habla de «Saverna» (pág. 64), [Saverne] y de «Falseburg» (pág. 78) [Phalsburg, cerca de Saverne]

Paralelos: Berlaimont (1551): «El V. Capitulo, platicas familiares siendo en el meson», inspiración para Minsheu (1599): «Diálogo quarto, entre dos amígos llamádos el uno Mora, el otro Aguilar y un moço de mulas y una Ventéra, tratán se en el de las cósas tocántes a el camíno con muy graciósos dichos y chistes", plagiado en Oudin (1608), Dialogos apazibles, a su vez copiado por Franciosini (Dialoghi piacevoli, 1626) y Sobrino (Diálogos nuevos en español $y$ francés, 1708), etc.

Este Coloquio II explica el viaje con detalle en diversas secuencias o situaciones: preparativos (regateo del precio del porte al conductor), primera jornada, comida en el viaje, continuación del viaje, cena, partida de naipes antes de irse a la cama, de modo que los personajes se acuestan tarde pero se levantan pronto, hacen cuentas y parten para París, adonde llegan en el...

[3] ... «Coloquio tercero. De la casa Bartolome, Pablo, Francisco, Conrado, el mesonero de Paris, Olivar, el criado, Daniel, labrador, Lucas, mesonero del dicho Daniel» (título y personajes)

Resumen: los caballeros de Estrasburgo buscan a un amigo compatriota en París, que les explica cómo es la ciudad y las diferencias de costumbres, así como les recomienda a su mismo posadero, con el que conciertan alojamiento.

Paralelos: bastante original, sólo quizá podemos señalar un leve parecido con la consignación de diferencias culturales del Espexo de la gramática en diálogos de Ambrosio de Salazar (1614) (cf. MauxPiovano 2005)

[4] «Coloquio quarto. Del Iuego de pelota. Henrique, Antonio, Miguel, Nicolas, jugador. Lubino, chaçador. Teofilo, maestro del juego de pelota» (título y personajes) 
Resumen: los amigos Henrique y Antonio deambulan juntos en busca de pasatiempos, hasta que deciden ir a un jeu de paume ('juego de pelota'), antecedente del tenis: pelotean, juegan un par de partidas con otros caballeros (juegos con puntaje de 15, 30, 45 y ventaja); los ayuda y asiste un chazador y el público de la galería actúa de árbitro; hacen cuentas al final (se puede ver una imagen de la época en Bonhomme 1991: 24).

Paralelos: no hay precedentes, pero sí fortuna posterior por medio de plagio segmentado, en las colecciones de A.F.K. (Teutsch-Spanischer Richtiger Und Regul-mässiger Sprach-Zeiger. Nürnberg: Johan Leonhard Buggel, 1712) y Moratori (Instrucion fundamental Para Aprendèr el idioma español... Nurenberg: a costa de Pedro Conrado Monath, 1723)

\section{Características lingüísticas}

Los diálogos de Garnier forman parte de un género pedagógico escrito que podemos denominar diálogo escolar, utilizado para enseñar lenguas en la época y que, aunque pueda hacer una buena mímesis de la oralidad y lograr una creíble oralidad fingida, no hay que confundir con una conversación coloquial (oral), debido a que la oralidad pura sólo llega o se oye en el diálogo escolar por escrito tras pasar por diversos filtros que la atenúan y adulteran (cf. Sáez Rivera 2005a, 2008a: 1173-1213)

\section{Filtro 1 : Filtro (orto)gráfico: ortografía idiosincrásica de Marcos Fernández}

Conforme hemos señalado en otras ocasiones (Sáez Rivera 2005b, y en prensa), Marcos Fernández dice emplear una ortografía propia, según él, «la verdadera Ortografia âsta âhora inorada» (Fernández 1655: [ $\left.{ }^{*} 1\right]$ r), en todos sus escritos, a lo cual no se escapa su propia versión de los diálogos de Garnier, aunque en la reedición de 1659 el editor corrige o no respeta del todo lo que hemos dado en llamar «ortografía idiosincrásica» del autor.

Los principales rasgos idiosincrásicos o peculiares de la ortografía de Fernández son la sustitución - grosso modo - de $h$ por acento circunflejo, el empleo de -yi- para /y/ o /í/, así en ayier /y/ o ayi /í/, o el empleo de gue- (Guelgome, etc.) por hue-. En todo caso, estas y otras medidas ortográficas producen la inscripción de Fernández en la tradición fonológica simplificadora que arranca de Quintiliano, de donde se transmitió a Nebrija y cuyo más radical y conocido representante en el Siglo de Oro fue Gonzalo 
de Correas, al que quizá conoció (o al menos su obra) el mismo Fernández en Salamanca. Ello explica la reacción antilatinizante de Fernández, con la supresión de grafías latinizantes $(p h, t h \ldots)$ - excepto qua- (quanto, quando...) - y la simplificación de grupos cultos.

De todos modos, el efecto logrado es el de una ortografía más cercana a la oralidad de lo habitual en la época, aunque también hay detalles de la escritura formal-administrativa, como el empleo de abreviaturas como N. = nescio (según aclaran la abreviatura Salvador/ Lodares 1996: 192-193): «B. No os lo â dicho el Señor N?» (p. 46).

\section{Filtro 2: Tradición literaria}

Garnier (y con él Fernández) se inscribe en la tradición de oralidad fingida del diálogo escolar renacentista (Erasmo, Vives) con mejor éxito que otros diálogos para la enseñanza de lenguas vulgares. Así, aunque es aún incapaz de reproducir algunos elementos de la oralidad espontánea dialógica como son las interrupciones, solapamientos o falsos comienzos, sí es capaz de incluir de forma mimética numerosos elementos, que repasaremos a continuación nivel a nivel lingüístico:

Fonética

En primer lugar destaca la frecuente aparición de exclamaciones (Briz 2001: 98) en forma de interjecciones (propias e impropias), onomatopeyas y vocativos. Así, encontramos interjecciones como $o(h)$ 'sorpresa, contrariedad', (h)ola 'llamada, especialmente a criados', ora sus, ea o vamos como apoyos del imperativo o de la interrogación, aparte de la onomatopeya de la risa ( $\hat{A}$ $\hat{a} \hat{a})$ y diversos vocativos ${ }^{12}$.

(1) $H$. Ea, Señores, jugaremos?

M. Si, quando gustaredes. [p. 212] [interjección]

(2) $M$. Corred, Señor; tomad la volando, por que dará mala caida.

$N$. O! como ê êcho un mal golpe?

$M$. Vos os apresuarais mucho; vos no teneis paciencia.

$N$. Sois vos, que me decis que corra.

M. Si; mas ai raçon para todo; âse de correr con discrecion.

$N$. No ai remedio: ellos tienen la primera partida. [pp. 216, 218] [interjección]

12 En todos los ejemplos de aquí en adelante, utilizaré énfasis en negrita y, a veces, subrayado. 
(3) A. Estais apercebidos, Señores?

N. Si : jugad, quando gustaredes.

$H$. Tomad esa, Señor. Corred, corred.

$A$. Nuestro es: quarenta i cinco.

$H$. O que alli ganamos una linda chaça! animo; la otra es pequeña: si la ganamos, tendremos tres juegos.

$M$. Buen Dios, como servis tan mal, Señor?

A. Lo peor que puedo; no dudeis dello. [pp. 210, 212] [interjección]

(4) I. Es menester que yo os presente, pues que no tomais: ola muchacho echa aqui vino para todos. Que vino os agrada de bever, Señor?

$P$. Del que fueredes servido, Señor, todo me es uno no reparo en eso. [p. 26] [interjección]

(5) A. Està mi camisa seca? dadmela.

$L$. Tened, Señor: veis la aqui; està bien enxuta.

$M$. Ora sus, quanto devemos?

L. Señores, yo voy a llamar mi amo. [p. 226] [interjecciones]

(6) $P$. A ora pues, que me quereis dar, yo os enseñaré un arte para no perder jamas vuestro cuchillo?

F. O! vos os quereis burlar de mi.

$P$. No, yo os juro; como me ê de burlar de vos? yo no tengo de vuestro dinero.

$F$. Enseñadmelo pues, yo lo retendré por amor de vos.

$P$. Yo os lo enseñaré bien: abrid las orexas, i oid con atencion.

F. Yo oigo.

$B$. Cierto vos sois donoso, i vendeis bien vuestros donaires.

$P$. Vos me perdonareis: mas sabeis, que quando se enseña algo, no deve de ser negligente.

$F$. Es verdad: veamos pues ese arte, yo os suplico.

P. Es, que todas, i quantas veces aveis enbainado vuestro cuchillo, bevereis una vez, i no lo olvidareis jamas.

$B$. A â â, esa vale mucho.

$F$. Bien sabia yo eso, mas yo pensava que queriades decir otra cosa. [pp. 90-92] [interjección, risa]

(7) F. Esta pagado todo, Señor mesonero? estais satisfecho?

$G$. Si, Señor: pasando otra vez por aqui, os ruego de no tomar otra posada.

$P$. Asi âremos, Señor mesonero, yo os asiguro.

$D$. Vamos, Señores. Sois servidos de subir?

$F$. Està todo adereçado, cochero? estan nuestras maletas en el coche?

$D$. Si, Señor : no tengais cuidado de nada; todo està bien. [pp. 112-114]

[interjección + vocativos] 
Morfología

Formas verbales en proceso de cambio antes en la oralidad

Según mostramos en Sáez Rivera (2008a: 1277-1279), en la época el proceso de cambio de la segunda persona verbal del pretérito indefinido amastes $>$ amasteis se produjo antes en la oralidad que en la escritura, de ahí que se documente antes y más en textos dialogales, de lo cual es una muestra la versión de Fernández de los diálogos de Garnier:

(8) B. Por que no almorçasteis?

$P$. Por que me levante mui temprano, i no tenia ningun apetito. [p. 64]

\section{Diminutivos}

Herramienta principal de la atenuación típica de la oralidad coloquial es el empleo del diminutivo (Briz 2001: 150), recurso más frecuente en otros autores como Barnabé en sus Discursos familiares $(1660)^{13}$, pero que también podemos encontrar en Fernández, en cuyo texto apenas documentamos «a la mañanita» frente a «de grand matin» del texto en francés que ha servido de fuente para el español (con probable contaminación a veces de la versión italiana):

(9) I. Estad preparado a la mañanita. [col. fr.: de grand matin]

$P$. Yo estare preparado a las cinco ôras, con el favor de Dios. [pp. 36-38]

\section{Deíxis ad oculos}

También es típica de la oralidad, especialmente coloquial, la deíxis ad oculos o exofórica a la situación de uso (Briz 1996: 34-42), de ahí la aparición de adverbios deícticos de lugar (aquí-ayi-allí-allá), tiempo (aôra), modo (asi), de demostrativos o de estructuras mostrativas del tipo veis/ ved, etc.:

(10) B. Estas savanas no son limpias, como me parece.

$T$. Perdonadme, Señor; no â dormido persona ninguna en ellas despues que se sacaron del cofre.

$F$. Dexadme ver. Por mi fé, que no puedo creer que ân entrado en lexia, por que son mui blandas.

$T$. Eso es verdad, Señor; mas iço gran viento, quando las en jugamos.

$F$. Aced traer otras, nosotros lo pagaremos bien.

$T$. Cierto, Señor, no las podremos dar que sean mas blancas, ni mas limpias.

$P$. Devese de creer, pues que ella jura.

$B$. Pues que las traigan mas delgadas, porque estan son mui gruesas.

$T$. Veis ayi las mejores, i mas limpias que a ôra tenemos.

$F$. Ea, descubrid la cama, corred las cortinas, i traednos el orinal.

13 Editados por Messner (2000). 
T. Veis lo ayi, Señor. [pp. 106, 108] [deíxis ad oculos + pues marcador, imperativo más causal de la enunciación con porque]

Sintaxis

Sin embargo, lo más característico de la lengua oral-coloquial, según señala Narbona $(1989,1994)$ es su peculiar andadura sintáctica, aunque el estudio de tal nivel en la oralidad haya sido habitualmente marginado hasta hace poco. Por tanto, es en este nivel en el que más reparamos, ya que es del que más ejemplos hemos encontrado.

Duplicación clítica de objeto

La duplicación clítica de objeto siempre ha sido (y sigue siéndolo) más frecuente en la oralidad, e igualmente ocurría en la época (Saéz Rivera 2008a:1298-1505). Es este, sin embargo, el rasgo que imita con menor frecuencia y mayor limitación Fernández, pues sólo escribe ejemplos de duplicación de pronombres de objeto, la única estructura de duplicación clítica ya gramaticalizada a principios del XVII, según Rini (1992: 129):

(11) B. Ea, Señores; tocame ami de dar: quantos naipes ê dedar a cada uno?

Topicalizaciones / frontalizaciones enfáticas

Destaca también en el discurso oral la mayor importancia dada al orden informativo o pragmático frente al orden sintáctico (Givón 1979; Briz 2001: 77-80), de ahí que encontremos topicalizaciones o tematizaciones/ frontalizaciones enfáticas, en forma de "preaserción» (Blanche-Benveniste 1998: 26):

(12) A. Señores, no olvideis los alfileres de las moças?

$P$. Como? no es para vosotros todos?

$A$. No, Señor; nosotros nonos metemos con los moços.

F. Que? teneis vuestra bucha aparte?

$A$. Si, Señor.

$P$. Dad las alguna cosa, Señor Bartolome, nosotros os lo bolveremos todo.

$B$. Tomad aqui pues para vosotras.

A. Agradecemos lo Señores. [pp. 116] [que topical]

(13) B. Mas vos sabeis bien que ê estado casi cinco semanas en el campo.

$P$. Cierto que no ê oido nada. [pp. 44, 46] [cierto con frontalización enfática] 
Repeticiones

Igualmente destaca en el discurso oral el exceso de redundancia y repetición léxica (Narbona 1989: 181-183; Blanche-Benveniste 1998: 114; Briz 2001: 71-72), frente al discurso escrito formal en el que prima - al menos en español - el principio retórico de la variatio, sobre todo léxica.

Las formas de repetición pueden ser enfáticas, si son contiguas, inmediatas, o meramente cohesivas (la repetición léxica es uno de las posibilidades de crear cohesión textual, según Halliday y Hasan 1976), si la repetición no es contigua, sino mediata (otras palabras ocupan el espacio entre una y otra repetición), con el efecto de que se facilita el procesamiento (la variación léxica exige más atención y un mayor esfuerzo cognitivo para hallar las equivalencias referenciales):

Repeticiones enfáticas o iteraciones

Se trata de lo que Vigara Tauste (1992: 147) llama iteración o «repetición insistente y redundante del término o valor intensificado»:

(14) Iteraciones

(14.1) Adverbios: «P[ablo]. Veis, como platicando se pasa el tiempo, aora aora [voilà] estaremos en la villa.» (pág. 18); P[ablo]. No, no, [Non, non] Señor, yo lo daré al muchacho.» [p. 32]

(14.2) Verbos: «I[acob]. Teneis vos naturaleça de gato? temeis os [sic] del agua? vamos vamos [allons, allons] : no somos de sal, no nos derreteriemos » [pág. 6]; "D[avid cochero]. Ola, Señores; levantad os, levantad os [debout, debout], que âceis tan tarde en la cama?» [p. 60]

(14.3) Adjetivos: "N[icolas]. Atento, atento [Prez, prez], Señor; tomadla bolando.» [p. 196]

(14.4) Interjecciones: "I[acob]. A a a, [Ha ha ha], yo lo concedo, bueno es de envejecer, siempre se aprende alguna cosa.» [p. 30]; "D[aniel]. O ô [Ha $h a]$, Señor; quien pensara que estuviesedes aqui? sed bien venido, i vuestra compañia.» [p. 126]; «N[icolas]. Ea ea [Là là], jugad solamente, i no esteis burlando.» [p. 218]; «A[ntonio]. Animo, animo, Señor» [p. 220].

Cohesiva

Uno de los muchos ejemplos que podemos encontrar:

(15) N. Vamos al juego de pelota: puede ser que veamos jugar alguna buena partida.

$H$. Ai juegos de pelota en esta villa?

$N$. Si cierto, Señor. Como? que pensais quê en tal villa como esta, no avia de âver juego de pelota?

$H$. No, Señor; yo pregunto, por que me parece que los juegos de pelota, son 
raros en esta tierra.

$N$. Antes de aôra ân sido raros; pero aôra los Señores, que ân caminado por Francia Italia, ân mandado fabricarlos en todas sus villas. (p. 168)

\section{«Figuras» sintácticas}

La profesora Blanche-Benveniste (1998), dentro del Groupe Aixois de Recherches en Syntaxe (GARS), ha propuesto un análisis de las producciones orales y escritas en forma de "grillas» de modo que se alinean verticalmente las unidades léxicas y sintácticas producidas según los recursos o "figuras» sintácticas típicos de la producción oral, en las que el eje paradigmático se plasma sintagmáticamente. Las figuras que sugiere Blanche-Benveniste son la simetría (una especie de anáfora más paralelismo) y la enumeración (mero paralelismo por la producción de listas de elementos con una misma función sintáctica), a las que López Serena (2007: 306-323), que acoge y aplica el modelo de análisis del GARS y de Blanche-Benveniste (1998), añade las escaleras, mediante las cuales un elemento lingüístico es repetido y luego ampliado sintácticamente, en una especie de anadiplosis:

Simetrías

(16.1) I. Teneis vos naturaleça de gato? temeis os del agua? vamos vamos: no somos de sal, no nos derretiremos. (p. 6) [simetría]

(16.2) [Grillas:] Teneis vos naturaleça de gato? temeis os del agua?

vamos

vamos: no somos de sal, no nos derretiremos.

(17.1) I. Si lo âceis a veces: mas creo que lo âceis de avaricioso, por no gastar dinero. [p. 8] [simetría]

(17.2): [Grillas:] I. Si lo âceis a veces: mas creo que lo âceis de avaricioso, por no gastar dinero.

(18.1) I. Coged desas cereças, ciruelas, mançanas, peras, i avellanas.

$P$. No veis como âgo yo?

I. Coged a vuestro gusto, i lo que os agrada mejor.

$P$. Asi âgo yo, mas vos no cogeis ni comeis?

I. Por mi parte, no gusto mucho de la fruta, fuera las uvas.

$P$. Comed destas cereças, que son buenas, i maduras.

I. Yo como bien como veis. (p. 14) [Simetría enfática + figura de enumeración] 
(18.2) [Grillas:] I. Coged desas cereças,

$$
\text { ciruelas, }
$$

mançanas,

peras,

i avellanas.

$P$. No veis como âgo yo?

I. Coged a vuestro gusto, i lo que os agrada mejor.

$P$. Asi âgo yo, mas vos no cogeis

ni comeis?

I. Por mi parte, no gusto mucho de la fruta, fuera las uvas.

$P$. Comed destas cereças, que son buenas, i maduras.

I. Yo como bien como veis.

\section{Escaleras}

(19.1) $P$. No tenemos entonces necesidad de entrar en la aldea?

I. No, no queriendo. Veis alli la puerta, entrad si gustais. [p. 12] [Escalera]

(19.2) [Grillas:] P. No tenemos entonces necesidad de entrar en la aldea?

I. No,

no queriendo. Veis alli la puerta, entrad si gustais.

(20.1) P. A si es, yo pienso que no son mas que las cinco i media.

I. No, no puede ser mas. [p. 18] [Escalera]

(20.2) $P$. A si es, yo pienso que no son mas que las cinco i media.

\section{No,}

no puede ser mas.

Otras estructuras conversacionales

Justificación pragmática

Es típico del discurso coloquial en español el empleo del esquema «Acto aseverativo porque Acto justificativo» (Briz 1998: 192), o más habitualmente "Acto directivo porque Acto justificativo", que sintácticamente se suele y se puede plasmar también mediante un imperativo y una pausa seguida de una causal de la enunciación, típicamente introducida por que (como vemos en 21), pero también con porque (conforme ya vimos en 10). La justificación pragmática es necesaria, puesto que al ser un acto directivo amenazante para la face o imagen negativa del receptor, el emisor debe atenuarlo -por ejemplo- apelando a la racionalidad de una justificación lógica, y a la postre persuasiva, que se presupone que rige el comportamiento humano ( $c f$. Brown y Levinson 1987 [1978]):

(21) P. Comed destas cereças, que son buenas, i maduras. (p. 14) 


\section{Construcciones eco}

Uno de los testimonios más interesantes encontrados en el texto de Garnier-Fernández es la aparición de estructuras tan típicamente orales como las construcciones eco, en este caso interrogativas eco (Briz 2001: 73-75), por la que se repite, introducida por un que reasuntivo, una pregunta que no ha sido correctamente atendida por el receptor. Destaca además que la estructura ya está en el texto original de Garnier (del cual proporcionamos algún fragmento entre corchetes), que traduce con acierto Fernández:

(22) $F$. Yo creo que es mui peligroso este bosque.

$B$. Yo lo pienso tambien, i creo que â sido un nido de ladrones.

$P$. Es verdad: i por eso, como oyi decir, ân cortado los arboles al rededor

del camino: por que ninguno osa de pasarlo. No es verdad, cochero?

$D$. Que señor?

$P$. Que se acortado una partida destos arboles, por causa de los salteadores? [P. Que l'on a abbatu une partie de ce bois a cause des voleurs?]

$D$. Si, Señor; por que no pasava nadie sin ser robado, i despoxado. [pp. 78, 80]

Marcadores metadiscursivos

Abundan aparte en la oralidad coloquial, pero también en estos diálogos de Garnier-Fernández, los marcadores metadiscursivos que sirven para señalar las partes del discurso, la estructura conversacional, y actúan como partículas de puntuación, a modo de pausas oralizadas (Briz 2001: 207).

Destaca en el texto de Garnier el empleo de pues $^{14}$ como marcador iniciador de turno y recuperación de un turno perdido (Briz 2001: 209), conforme se puede ver en (23), y de bueno ${ }^{15}$, en el que podemos ver su desarrollo como marcador desde su interpretación literal en (24), a la expresión de asentimiento en (25) y el funcionamiento como marcador demarcativo de turno o secuencia en (26).

(23) I. Yo vine por la mañana, i despues de medio dia, i a la tarde.

$P$. Bien lo creo: mas sabed, que a las diez voi a subir a cavallo, i a la una despues de medio âsta las tres aprendo a esgrimir.

I. Pues como no estais aora en casa del esgrimidor?

$P$. Yo no me siento oi de umor, ni bien dispuesto para ello. Mas no gustais de asentar os un poco?

I. No es menester, yo vengo, para que nos vamos juntos a pasear, agradando os. [pp. 4, 6] [pues como marcador iniciador de turno]

14 Del cual Silvia Iglesias (2000) ofrece un estudio diacrónico hasta el siglo xv.

15 Para el uso de bueno en la actualidad, marcador típicamente oral y por ello coloquializante en la escritura, $c f$. Casado Velarde (1993: 39-40). 
(24) I. Buenas tardes, Señor. Como estais?

$P$. Bueno, gracias a Dios, para serviros. Es maravilla de veros, Señor. (p. 4) [ritual de saludo + bueno léxico]

(25) B. Comeremos alli?

$D$. Si, Señor; por que es larga la distancia.

$P$. Yo creo que vos teneis por costumbre de comer ayi al medio dia, partiendo por la mañana de Strasburgh.

$D$. Es verdad, Señor, quando partimos por la mañana.

$P$. Bueno bueno, tanto mejor; yo me alegro; por que no almorce sino mui poco esta mañana. (p. 64) [bueno asentimiento]

(26) A. Estais apercibidos, Señores? estais.

$M$. Si, Señor; jugad quando fueredes servido. Mas con quantas partidas acaberemos el juego?

H. Bueno; no âvemos âblado deso. Con dos partidas, si os parece. [p. 204] [marcador]

Léxico

Tradicionalmente se ha reducido el estudio de lo coloquial-oral a lo léxicamente pintoresco, concepción que aún es muy frecuente entre hablantes no formados en lingüística o en proceso de formación (Briz 1996: 12). Ello no quita que efectivamente sean frecuentes en el habla coloquial algunas constantes léxicas, como la frecuencia de expresiones fraseológicas (locuciones, refranes, sentencias), de la que podemos ver una muestra en 27 o la alusión a funciones corporales íntimas que vimos en (10), donde se hablaba con toda naturalidad de un orinal.

(27) I. Poned os alli sin cerimonia, por que ese es el lugar de los convidados, no sabeis el proverbio que dice, el se deve estar, adonde el guesped le manda asentar. [col.fr.: Tel se peut seoir sans contredit, qui se met où son hoste luy dit] [p. 24] [fraseología + cortesía no verbal]

Pragmática

Rituales de saludo y despedida enmarcando conversaciones y secuencias conversacionales

Los diálogos y las secuencias dialogales están debidamente enmarcados por rituales de saludo, como los de (24) y de despedida como los de (28), que son naturales en la conversación coloquial:

(28) P. A Dios, Señor mesonero, âsta mas ver.

I. A Dios, Señores; ruego a Dios que os quiera guiar bien.

[p. 76] [ritual de despedida] 
Cortesía verbal

Pronombres y formas nominales de tratamiento

En este punto destaca que, al igual que ocurría con la duplicación clítica de objeto, la imitación de la oralidad no parece del todo perfecta, ya que, junto al empleo de vos para dirigirse a inferiores (ver 32), también se emplea como pronombre cortés a iguales y superiores si se ve acompañado de la adecuada fórmula nominal, del tipo señor (+ nombre/ oficio) - como en (2), (6), (7) o (31) - o maestro (+nombre de pila) ${ }^{16}$, por lo que es probable que se siga en parte la poética de la interlocución que estudió para el teatro lopesco Nadine Ly $(1981,2002)$, según la cual en el teatro o en la literatura (no olvidemos que los diálogos de Garnier-Fernández son también una pieza literaria), se podía realizar un uso pronominal ligeramente distinto al del código sociolingüístico ${ }^{17}$.

\section{Fórmulas de cortesía}

Aparte de pronombres en combinación con formas nominales de tratamiento, destaca la aparición de fórmulas de cortesía, muchas de las cuales son una lexicalización de estructuras condicionales en las que se dan opciones de actuación, siguiendo una de las máximas de cortesías formuladas por Robin Lakoff (1983), conforme podemos ver en (29) y (30):

(29) $F$. Ven aca, amigo, decidme adonde se va aqui a la secreta [la garde robe $=$ il necessario $]$ ?

T. Si sois servido, Señor, yo os llevaré alla. [p. 108] [fórmula de cortesía]

(30) F. Serà necesario que me âgais merced de me encaminar un buen sastre; por que me quiero vestir al uso de Francia.

$D$. Quando fueredes servido, yo sê un sastre, que no da ventaxa a ninguno desta villa. [p. 156] [fórmula de cortesía]

\section{Cortesía no verbal y comentarios metapragmáticos sobre cortesía}

Por otra parte, la cortesía implica no sólo un comportamiento lingüístico sino también paralingüístico, en lo que entran cuestiones de comunicación no verbal proxémica en relación al espacio, por ejemplo sobre quién, cómo y en qué lugar se sienta a una mesa (ver el ejemplo 27). También forma parte de la cortesía una conducta global sobre el que se hacen numerosos

16 «F[rancisco]. Dexadme a mi, yo lo llamaré bien, el me conoce bien. Ola o, maestro David./D[avid, cochero]. Que quereis, Señor?» (pág. 52)

17 Para más detalles sobre el empleo de formas de tratamiento en la versión de Fernández de los diálogos de Garnier, por ejemplo acerca de unas interesantes mezclas del paradigma de tú con el de vos, $c f$. Sáez Rivera (2008a: 932-934) 
comentarios metapragmáticos, de los cuales meramente damos unas muestras en (31)-(33):

(31) $P$. Vos sois mui cerimonioso, Señor.

I. Perdonadme, vos lo sois.

$P$. No cierto, yo no reparo en tampoco $[s i c]$. [p. 12] [comentario de cortesía]

(32) ora dadme vuestro platillo veis ai otro limpio.

$P$. No, no, Señor, yo lo daré almuchacho.

I. Yo imagino que no se allarà ômbre mas cerimoniero que vos, ôla Iuan quita alla ese platillo del, Señor, i dadle un limpio.

$P$. Yo no soi cerimoniero como vos decis, mas pues que ai aqui gente que sirve ala mesa, no seria raçon que yo me sirviese de vos.

I. Es cosa de poca inportancia, mas suplico os, bevamos.

$P$. Yo soi contento brindadme una vez, yo os âré raçon. [p. 32] [comentario de cortesía]

(33) P. Suplico os, Señores, lavemonos todos juntos sin ceremonias. [p. 70] [comentario de cortesía]

\section{Filtro 3 : pedagogía}

Disposición en columnas

El texto escrito de los diálogos está dispuesto en diferentes columnas según las lenguas recogidas en el compendio, en forma de traducción yuxtalineal, que permite observar con facilidad la equivalencia pragmática entre las diversas lenguas más que la comparación de sus estructuras lingüísticas, especialmente sintácticas, que facilita más bien la técnica de la traducción interlineal adoptada a partir del siglo xIX. La disposición en columnas facilitaba además el empleo de los diálogos como ejercicios de traducción : bastaba tapar la columna del idioma como lengua meta y objeto de la práctica para luego cotejarla con la traducción que hubiera hecho el aprendiz de esa lengua meta (Satorre Grau 2001).

Defecto pedagógico de Garnier-Fernández

Aparte de servir para ejercicios de traducción por escrito, los ejercicios se aprendían de memoria con objeto de tener en la punta de la lengua las palabras adecuadas en una situación precisa (cf. Satorre Grau 2001)18. A este respecto, los diálogos de la colección de Garnier que tradujeron Fernández y Donato son quizá demasiado largos para su memorización,

18 No tiene sentido por tanto hablar de un método conversacional para la época, pace Sánchez Pérez (1992), cf. Sáez Rivera (2005a). 
incluso para la época, de ahí su fragmentación en la posterior tradición editorial o "tradición de copias, alteraciones y adiciones encadenadas» (Sáez Rivera 2005a: 793): tanto A.F.K. (1712) en su Teutsch-Spanischer Richtiger Und Regul-mässiger Sprach-Zeiger como Moratori (1723) en su Instrucion fundamental para aprender el idioma español copian sólo secuencias de los diálogos Garnier-Fernández que facilitan su aprendizaje memorístico (Sáez Rivera 2008a: 1212). En todo caso, la longitud de los textos está mediada por su empleo para la enseñanza, frente a la libertad de duración que posee la conversación coloquial, que puede ser tanto muy larga como muy corta, según las circunstancias.

Pregramaticalización

A todo ello hay que unir que la lengua que aparece en los diálogos no es espontánea, sino que está pregramaticalizada, de modo que la redacción de los coloquios, a veces simplificada, está especialmente diseñada para enseñar ciertas estructuras lingüísticas, en todos los niveles ( $c f$. Besse 2001; Sáez Rivera 2005a, 2008a: 1185-1187):

1. Nivel fónico-gráfico: los diálogos sirven para la práctica de la lectoescritura.

2. Nivel morfológico: también se emplean para aprender inductivamente la flexión de las diferentes partes del discurso, especialmente el verbo (de ahí quizá la hiperabundancia de pronombres de sujeto que facilita el reconocimiento de la persona verbal); la pregramaticalización puede explicar además la anómala ausencia de pérdida de $d$ en imperativos de 2. ${ }^{a}$ persona del plural (ponedos) ${ }^{19}$, que facilitaría el reconocimiento de la forma verbal correcta conforme aparece sin os.

3. Nivel sintáctico: enseñanza inductiva del nivel sintáctico, que apenas desarrollan las gramáticas E/LE de la época, como es el caso de la propia Instruction espagnole accentuée de Fernández.

4. Nivel léxico: otras tradiciones editoriales emplean técnicas como la glosa léxica (diálogos de Minsheu y sus plagiadores) o el ofrecimiento de opciones sinonímicas (conforme ocurrre en las colecciones de Julliani o Moratori); más frecuente, y documentado en los diálogos que nos ocupan, es la inserción de retahílas de palabras de un mismo campo léxico que fungen a modo de pequeñas nomenclaturas o vocabularios temáticos (ver el convite de frutas del coloquio I, por

19 «I. Bien, no importa nada: asentemonos, por que la comida se resfria: tomad lugar Señor, ponedos alli, yo os ruego./ P. Asentad os, yo me asentaré aqui.»[p. 25] 
ejemplo 18.1), así como la estructuración del texto en torno a campos léxicos y guiones cognitivos implícitos (así el campo del juego de pelota en el coloquio IV: jugador-raqueta-pelota, chaza-chazador, agujerocuerda-galería, juego-15-30-45-ventaja-iguales); asimismo, se enseña fraseología.

5. Nivel pragmático: los diálogos sirven para entender el funcionamiento de los pronombres y fórmulas nominales de tratamiento y otras formas de cortesía; en otras tradiciones editoriales se insertan cuentecillos para salpimentar la conversación (tradición de Minsheu); se explican culturemas y diferencias culturales varias.

\section{Filtro 4 : contacto lingüístico}

Siempre que se produce una situación de contacto lingüístico prolongado, se ocasiona un debilitamiento de la norma lingüística, sobre todo en situaciones periféricas (Sala 1998: 47-49), como es el caso de Fernández, un español en Europa que ha perdido el contacto físico con su país y que se encuentra en la tesitura de ejercer de traductor de un texto en francés (la lengua de origen que sigue principalmente Fernández).

Por ello, encontramos en la traducción de Fernández diversas clases de interferencia lingüistica, según los cuatro tipos que distingue Kabatek (2000: 34-35), considerando que A equivale a francés y B a español, con una amplia zona de coincidencia $\mathrm{AB}$ :

1. Interferencia de $A$ en $B$ : en un texto de la lengua $B$ aparecen elementos de la lengua $A(-A B)$, inexistentes en $B(+A B)$, lo que denominaremos interferencia de transposición, de ahí ejemplos como âcer raçon = faire raison (34)-(35) o que con el sentido restrictivo de solamente (36)

(34) I. Es cosa de poca inportancia, mas suplico os, Bevamos.

$P$. Yo soi contento brindadme una vez, yo os âré raçon. [P. Ie le veux bien, beuvez à moy, je vous feray raison.] [p. 32] [interferencia léxica: faire raison]

(35) «Faire raison (à qqn d'une santé qu'il a portée). Lever son verre et boire à la santé de celui qui vient de boire à la vôtre. Du bras droit il me faisait raison des santés que je portais à sa famille (RABAN, MARCO SAINTHILAIRE, Mém. forçat, t. 1, 1828-29, p. 93). Vous ne refuserez pas de me faire raison encore une fois, dit-il en versant encore à boire et en forçant le créancier à trinquer avec lui (MURGER, Scènes vie boh., 1851, p. 240).» (TLF)20

$20 \mathrm{http://atilf.atilf.fr}$ 
(36) I. Señores entrad en esta sala, si gustais; yo daré orden que la comida sea preparada; si gustais entretanto de bever una copa de vino, no teneis que decirlo.

$B$. No puede âcer daño, para ver si el vino es bueno.

[pp. 66-68] [interferencia sintáctica: que restrictivo]

2. Interferencia negativa: en un texto de la lengua B aparecen con preferencia elementos de la zona análoga en las dos lenguas (o idéntica) $\mathrm{AB}$; es decir, las posibilidades de la zona $\mathrm{B}(-\mathrm{AB})$ no se realizan (interferencia de convergencia), con ejemplos como el exceso de frecuencia del pronombre personal de sujeto (también por razones pedagógicas) que vemos en (37), el empleo de pequeño como diminutivo léxico en (38) o (39) por influencia del francés (que consignamos según el texto original entre corchetes), así como la retención o reaparición de arcaísmos como el partitivo (40), o el vos cortés, etc.

(37) P. Quantas veces aveis venido aqui, que no me ayais âllado?

$I$. Yo ê venido mas de seis o siete veces, mas nunca os âllé.

$P$. Yo no sê pues, a que ora venisteis.

I. Yo vine por la mañana, i despues de medio dia, i a la tarde. [p. 4] [interferencia: exceso de pronombre de sujeto]

(38) $P$. Es lexos de aqui?

I. Aun no dos pequeñas leguas. [petites leües] (p. 36) [interferencia: pequeño = diminutivo léxico]

(39) $D$. Beved antes una copa de vino, Señor guesped.

L. Cierto no tengo sed, Señor; yo os agradezco de buen coraçon.

$D$. Suplico os, que no me lo reuseis : bien bevereis esa pequeña copa. [ce petit verre là] [pp. 148-150]

(40) P. Vos decis bien, es necesario de bever antes de comer de las cereças, por que el vino no sabe bien despues. [p. 97] [partitivo]

3. Interferencia negativa: en un texto de la lengua $\mathrm{B}$ se realizan con preferencia elementos de la zona no análoga o no idéntica de las dos lenguas $(-\mathrm{AB})$; es decir, las posibilidades de la zona $\mathrm{AB}$ no se realizan (interferencia de divergencia); no documento o no detecto ejemplos

4. Ultracorreción: por causa de las supuestas correspondencias regulares entre elementos de $\mathrm{A}(-\mathrm{AB})$ y elementos de $\mathrm{B}(-\mathrm{AB})$ las reglas de conmutación también se aplican a elementos de la zona análoga o idéntica, teniendo como resultado la creación de las formas inexistentes en $\mathrm{B}(+\mathrm{AB})$; tampoco documento o detecto ejemplos. 


\section{Conclusiones}

Con este trabajo, que se alía al de Luis Pablo en este mismo número de Recherches, pretendía llamar la atención sobre un texto injustamente olvidado o no suficientemente recordado de la tradición de enseñanza de lenguas mediante diálogos, con los méritos de su originalidad temática en los coloquios tres y cuatro, especialmente, y el calado de la lograda oralidad fingida (aunque con el único defecto de la interferencia lingüística del francés, de gran impronta en la lengua española de esta traducción de Fernández).

Aparte, los diálogos de Garnier-Fernández son un importante documento histórico en cuanto forman parte de lo que podemos llamar un costumbrismo internacional que nos muestra la vida cotidiana de Estrasburgo y alrededores a principios y mediados del siglo XVII.

Queda para otra ocasión una comparación más detallada de este diálogo con las técnicas de oralidad fingida de otros diálogos de la época, aunque el trabajo de Ana Mancera (2008) ya apunta en esa misma dirección. También convendría realizar una edición crítica del texto en sus diferentes versiones, y no sólo de la parte española que tenemos en preparación.

\section{Bibliografía}

Arellano, I. (2005): "Marcos Fernández[:] Olla podrida a la española», Príncipe de Viana, 236, pp. 967-968.

Balibar, R. (1985): L'institution du français. Essai sur le colinguisme des Carolingiens à la Republique, Paris, PUF.

Balibar, R. (1991): Le colinguisme, Paris, PUF.

Bareau, M. (1977): «Notes biographiques sur Carlos García», Bulletin Hispanique LXXIX: 1/2, pp. 155-176.

Besse, H. (2001): "Comenius et sa "méthode d'enseignement graduée" ", Langue Française 131, pp. 7-22.

Blanche-Benveniste, Cl. (1998): Estudios lingüísticos sobre la relación entre oralidad y escritura, Barcelona, Gedisa.

Bonhomme, G. (1991): De la paume au tennis, Paris, Gallimard.

Bourland, C. (1933): «The Spanish Schole-Master and the polyglot derivatives of Noel de Berlaimont's Vocabulare», Revue Hispanique LXXXI, pp. 283-318.

Breva-Claramonte, M. (1987): "A Re-Analysis of Juan Luis Vives' (1492-1540) 'Exercitatio linguae latinae'», en Hans Aarsleff et al. (eds.), Papers in the History 
of Linguistics, Amsterdam/Filadelfia, John Benjamins Publishing Company, pp. 167-177.

Briz, A. (1996): El español coloquial en la conversación: situación y uso, Madrid, Arco/Libros.

Briz, A. (2001): El español coloquial en la conversación: esbozo de pragmalingüística (nueva edición actualizada), Barcelona, Ariel.

Brown, P. y S. C. Levinson (1987)[1978] : Politeness. Some universals in language use, New York, Cambridge University Press.

Casado Velarde, M. (1993): Introducción a la gramática del texto, Madrid, Arco/ Libros.

Collet-Sedola, S (1996) : «Gramáticos y gramáticas: España en Francia (1600-1650)», en Ignacio Arellano et al., Studia Aurea. Actas del III Congreso de la AISO (Toulouse, 1993). I. Logroño, GRISO-LEMSO, pp. 161-168.

Fernández Ordóñez, I. (2001) : «Hacia una dialectología histórica. Reflexiones sobre la historia del leísmo, el laísmo y el loísmo», BRAE LXXXI, pp. 389-464.

Gyvón, T. (1979): "From Discourse to Syntax: Grammar as a Processing Strategy», en Syntax and Semantics, Vol. 12, New York, Academic Press, pp. 81-112.

Kabatek, Johannes (2000): Os falantes como lingüistas: tradición, inmnovación e interferencias no galego actual, Santiago de Compostela, Edicións Xerais de Galicia.

Halliday, M. A. K. y R. Hasan (1976): Cohesion in English, Londres, Longman.

Iglesias, S. (2000): «La evolución histórica de pues como marcador discursivo hasta el siglo XV», BRAE, LXXX: CCLXXX, pp. 229-237.

Lakoff, R. (1983) : «The Logic of Politeness, or Minding P's and Q's», Proceedings of the Ninth Regional Meeting of the Chicago Linguistic Society, pp. 345-356.

López Serena, A. (2007): Oralidad y escrituralidad en la recreación literaria del español coloquial, Madrid, Gredos.

Ly, N. (1981): La poétique de l'interlocution dans le théâtre de Lope de Vega, Bordeaux, Université.

Ly, N. (2002): «La interlocución en el teatro del Siglo de Oro: una poética de la interferencia», Criticón 81-82, pp. 9-28.

Mancera Rueda, A. (2008): «Rasgos de Sintaxis Oral-Coloquializada en los Diálogos de los Siglos Xvi y Xvir Destinados a la Enseñanza de Español a Extranjeros», Boletín de la Real Academia LXXXVIII : CCXCVIII, pp. 229-258.

Maux-Piovano, M.-H. (2005): "La rôle de l'interlocuteur dans Le Miroir de la grammaire en dialogues d'Ambrosio de Salazar (1614)», Dialogue et Intertextualité, Nancy, Université de Nancy II, pp. 124-141.

Messner, D. (ed. fac. y coment.) (2000): Los manuales de español impresos en Viena en el siglo XVII, 2 vols., Salzburgo, Institut für Romanistik der Universität Salzburg. Meyer, Ph. (2008): Histoire de l'Alsace, Saint-Amand-Montrond, Perrin. 
Niederehe, H.-J. (1999): Bibliografía cronológica de la lingüística, la gramática y la lexicografía del español (BICRES II). Desde el año 1601 hasta el año 1700, Amsterdam y Filadelfia, John Benjamins.

Nuño Nieto, M. (1990): Diario del Conde Pöting. Embajador del Sacro Imperio. Madrid (1664-1674), 2 vols., Madrid, Biblioteca Diplomática Española Fuentes 1.

Pablo Núñez, L. (2007) «La rama textual más tardía derivada del vocabulario de Berlaimont (ca. 1527/ 1530): El pequeño vocabulario o nueva introducción a la lengua francesa de Bruselas, 1813-1842», Actas del VII Congreso Nacional de la AJIHLE (Alcalá de Henares, 2007) (en prensa)

Pablo Núñez, L. (2010): «Ediciones e historia textual de los diálogos plurilingües de Philippe Garnier», Recherches 5.

Pelorson, J. M. (1969) : «Le docteur Carlos García et la colonie hispano-portugaise de Paris (1613-1619)», Bulletin Hispanique LXXI / 3-4, pp. 518-576.

Rini, J. (1992): Motives for Linguistic Change in the Formation of the Spanish Object Pronouns, Newark, Juan de la Cuesta.

Rossebastiano, A. (2003) : «La tradition des manuels polyglottes dans l'enseignement des langues», en S. Auroux (ed.), History of Linguistics 1999: Selected Papers from the Eighth International Conference on the History of the Language Sciences, Amsterdam/Nueva York, John Benjamins Publishing Company, pp. 688-698.

Sáez Rivera, D. M. (2005a): «La explotación pedagógica del diálogo escolar en la didáctica del español (ss. XVI-XIX)», en M.a Auxiliadora Castillo Carballo et al. (eds.), Las gramáticas y los diccionarios en la enseñanza del español como segunda lengua: deseo y realidad: Actas del XV Congreso Internacional de ASELE, Sevilla, Universidad de Sevilla, pp. 792-798.

Sáez Rivera, D. M. (2005b): «La Olla podrida a la española (1655) o los presuntos entretenimientos de un maestro de lenguas del siglo XVII", en M. ${ }^{a}$ Carmen Cazorla Vivas et al. (coords.), Estudios de historia de la lengua e historiografía lingüística: Actas del III Congreso Nacional de la AJIHLE (Jaén, 27, 28 y 29 de marzo de 2003), Madrid, AJIHLE, pp.457-467.

Sáez Rivera, D. M. (2008a): La lengua de las gramáticas y métodos de español como lengua extranjera en Europa (1640-1726), Madrid, Servicio de Publicaciones de la Universidad Complutense: <http://www.ucm.es/BUCM/tesis/fll/ucm-t30253. pdf $>$.

Sáez Rivera, D. M. (2008b) : «La interferencia del italiano en los métodos de E/LE en Europa (siglo XVI-principios del siglo XVIII)», El valor de la diversidad [meta] lingüística: actas del VIII Congreso de Lingüística General (23-28 de junio de 2008), Madrid, UAM [CD-ROM] [en línea] <http://elvira.lllf.uam.es/clg8/actas/ index.html>.

Sáez Rivera, D. M. (2008c): «Marcos Fernández: "Capítulo y explicación de la palabra hidalgo o hidalga", en Olla podrida a la española... (1655)», Anales Cervantinos, XL, pp. 283-310. 
Sáez Rivera, D. M. (en prensa) : «La edición de textos con ortografía idiosincrásica: el caso de Marcos Fernández, gramático y ortógrafo del siglo XviI », Philologia Hispalensis.

Sáez Rivera, D. M. (ed.) (en preparación): Marcos Fernández: texto crítico español de la Gemmmulae linguarum de Philippe Garnier, Anexos Lemir.

Sáez Rivera, D. M. y C. Vaíllo (eds.) (en preparación): Marcos Fernández: Olla podrida a la española y Ramillete espiritual, Alcalá de Henares, Centro de Estudios Cervantinos.

Sala, M. (1998). Lenguas en contacto, Madrid, Gredos.

Salvador, G. y J. R. Lodares (2001)[1996]: Historia de las letras, Madrid, EspasaCalpe.

Sánchez Pérez, A. (1992): Historia de la enseñanza del español como lengua extranjera, Madrid, SGEL.

Satorre Grau, F. J. (2001): «El diálogo bilingüe de principios del siglo XVII como ejercicio de traducción», en M. Maquieira Rodríguez et al. (eds), Actas del II Congreso internacional de la SEHL, Madrid, Arco/Libros, pp. 875-883.

Le Trésor de la Langue Française Informatisé: <http://atilf.atilf.fr>.

Vaíllo, C. (2006): «La sátira de un expatriado español: la Olla podrida (1655), de Marcos Fernández», en C. Vaíllo y R. Valdés (eds), Estudios sobre la sátira española en el Siglo de Oro, Madrid, Castalia, pp. 151-178.

Vigara Tauste, A. M. ${ }^{a}$ (1992): Morfosintaxis del español coloquial: esbozo estilístico, Madrid, Gredos. 